\title{
Towards Climate Smart Farming-A Reference Architecture for Integrated Farming Systems
}

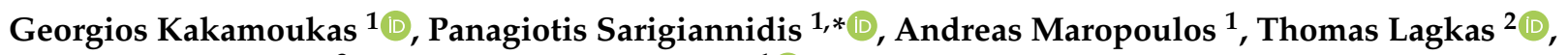 \\ Konstantinos Zaralis ${ }^{3}$ and Chrysoula Karaiskou ${ }^{1}$ D \\ 1 Department of Electrical and Computer Engineering, University of Western Macedonia, 50100 Kozani, Greece; \\ gkakamoukas@uowm.gr (G.K.); mpb00005@uowm.gr (A.M.); cnkaraisk@agro.auth.gr (C.K.) \\ 2 Department of Computer Science, Kavala Campus, International Hellenic University, \\ 65404 Thessaloniki, Greece; tlagkas@cs.ihu.gr \\ 3 Department of Agriculture, School of Agricultural Sciences, University of Western Macedonia, \\ 50100 Kozani, Greece; kzaralis@uowm.gr \\ * Correspondence: psarigiannidis@uowm.gr
}

Citation: Kakamoukas, G.;

Sarigiannidis, P.; Maropoulos, A.;

Lagkas, T.; Zaralis, K.; Karaiskou, C.

Towards Climate Smart Farming-A Reference Architecture for Integrated Farming Systems. Telecom 2021, 2, 52-74. https://doi.org/10.3390/ telecom 2010005

Received: 15 November 2020

Accepted: 26 January 2021

Published: 9 February 2021

Publisher's Note: MDPI stays neutral with regard to jurisdictional clai$\mathrm{ms}$ in published maps and institutional affiliations.

Copyright: $\odot 2021$ by the authors. Licensee MDPI, Basel, Switzerland. This article is an open access article distributed under the terms and conditions of the Creative Commons Attribution (CC BY) license (https:// creativecommons.org/licenses/by/ $4.0 /)$.

\begin{abstract}
Climate change is emerging as a major threat to farming, food security and the livelihoods of millions of people across the world. Agriculture is strongly affected by climate change due to increasing temperatures, water shortage, heavy rainfall and variations in the frequency and intensity of excessive climatic events such as floods and droughts. Farmers need to adapt to climate change by developing advanced and sophisticated farming systems instead of simply farming at lower intensity and occupying more land. Integrated agricultural systems constitute a promising solution, as they can lower reliance on external inputs, enhance nutrient cycling and increase natural resource use efficiency. In this context, the concept of Climate-Smart Agriculture (CSA) emerged as a promising solution to secure the resources for the growing world population under climate change conditions. This work proposes a CSA architecture for fostering and supporting integrated agricultural systems, such as Mixed Farming Systems (MFS), by facilitating the design, the deployment and the management of crop-livestock-=forestry combinations towards sustainable, efficient and climate resilient agricultural systems. Propelled by cutting-edge technology solutions in data collection and processing, along with fully autonomous monitoring systems, e.g., smart sensors and unmanned aerial vehicles (UAVs), the proposed architecture called MiFarm-CSA, aims to foster core interactions among animals, forests and crops, while mitigating the high complexity of these interactions, through a novel conceptual framework.
\end{abstract}

Keywords: mixed farming systems; climate smart agriculture; unmanned aerial vehicles; participatory learning; socio-economic modelling; internet of things

\section{Introduction}

Starvation is one of the biggest threats we are facing as humanity in the 21st century. The global demand for food is increasing, with recent studies forecasting that the global population will reach 9.5 billion people by 2050 [1], and more than $80 \%$ of available land is already cultivated [2]. Global demand for farming products is expected to increase by $70 \%$ for food production [3] and double for livestock products by 2050 [4]. However, agricultural production is strongly affected by the changes in climate conditions, such as rising temperatures [5], changing rainfall regimes [6] and variations in the frequency and intensity of extreme climatic events such as floods and droughts [7]. The estimated impacts of the climate change indicates that the yield loss could be up to $35 \%$ for rice, $20 \%$ for wheat, $50 \%$ for sorghum, $13 \%$ for barley and $60 \%$ for maize [8], and livestock production will be also negatively affected [4].

Both farmers and breeders need to find efficient and affordable methods in order to strengthen the resilience of agriculture and livestock farming against climate change. The 
concept of Climate-Smart Agriculture (CSA) reflects an ambition to improve the resilience of agricultural systems against climate change [9-11]. The Food and Agriculture Organization (FAO) of the United Nations defines CSA as agriculture that enhances productivity, improves resilience, reduces greenhouse gases (GHG) and facilitates the achievement of national food security and development goals [9]. The CSA includes both traditional and innovative approaches; and technologies that promote agricultural productivity, increase the stability at the farm level and foster the sustainability of the relevant value chains [11]. A system that adopts the concept of CSA is expected to increase its resilience against fluctuating climate conditions and therefore offer increased food production in the face of a changing climate and increased climate variability, while improving nutritional outcomes and reducing the carbon cost of farming and its contribution to GHG emissions [12-15].

It includes three major pillars: (a) increasing agricultural productivity; (b) increasing adaptive capacity at multiple scales (from farm to nation); and (c) reducing greenhouse gas emissions [12]. While there is a consensus on the potential of the CSA to support global food and nutritional security in less-favored conditions [11-13], CSA scholars have different perspectives when approaching the scaling of CSA options.

Integrated systems can combine crop production, livestock and forestry, supporting the production of at least three types of product from the same land area over a defined period [16-18]. These systems, based on inter-cropping, succession and/or rotation, can optimize the biological cycling of nutrients between plants and animals, and maintain longterm soil fertility [19-21]. According to the FAO, Mixed Farming Systems (MFS) are defined as farming systems managed by households and/or enterprises where crop cultivation and livestock rearing together form integrated components of a single farming system. MFS offer a lot of advantages, such as efficient use of resources by using crops and grassland to feed animals and fertilize their fields with manure from the animals, complementarities between crops and livestock and a flexibility that allows the adjustment of crop/livestock ratios in anticipation of risks, opportunities and needs [19,22,23]. Such context-relevant integration of crops and animals in the same system appears to support a biological, ecological and economic sustainability in the global food production chain $[17,18,23]$.

Nevertheless, MFS is not a universal panacea. The economic results of MFS are not as optimal as those of dedicated systems, especially considering the remuneration of labor. This is the reason why MFS are usually established in less-favored areas, e.g., mountains or sloppy areas, rough landscapes and heterogeneous terrains, where conventional farming or breeding does not usually take place [24]. In order to achieve a satisfied level of sustainability under these conditions, MFS should be able to effectively monitor the farm area, the animals and the grasslands. That is a difficult task, as MFS are extremely complex systems that include interactions between climate and weather, surface and sub-surface soil, crops, pastures, animal production and human management with economic components [25]. Critical features such as income stability and sustainability need special quality dimensions, criteria and indicators for the evaluation of trans-disciplinary processes [26]. Moreover, the climate, through weather patterns, as time progresses, play a decisive role, as rainfall and temperature drive the productivity, profitability and environmental health of the system. In addition, there is a need for reducing the energy needed to maintain the MFS operation. Another challenge is related to the role of research on MFS and the need for multi-disciplinary knowledge integration. A lack of integration between the research of different disciplines, such as agronomists, veterinarians and social scientists, limits the necessary integral vision and makes MFS difficult to implement [27]. Moreover, science lacks influence mainly because of biases towards academic research rather than practical applications [28]. It should be noticed, however, that this lack of knowledge integration is not always the case. There are countries that present significant progress in integrated farming systems from both practical and research perspectives [18]. The complexity of using MFS is increased when combining crop and livestock production due to the increase of the management demands of organizing multi-tasking activities. Considering that finding reliable labor with the required skills in specialized farming systems is difficult 
enough [29]; the problem becomes even more acute in a diversified farming system that requires the aggregation of various kind of knowledge and skills. Additionally, for a mixed farming system, the bureaucratic and administrative workload, which requires expertise that especially older farmers do not possess [29], is expected to increase compared to a specialized farm.

The success of MFS depends heavily on the aggregation of data, which is either produced by or affects the MFS, given that new technologies and solutions are effectively applied in order to collect, process and use it during decision making [30]. Precision agriculture is a method in which farmers optimize inputs such as water and fertilizer to enhance productivity, quality and yield. The fact that farmers are more precise with planting, harvesting, fertilizing leads to higher efficiency and productivity of the farm while ecological standards are respected [31]. Today, mobile applications [32], smart sensors [33], unmanned aerial vehicles (UAVs) [34], cloud computing [35] and edge computing [31] make precision agriculture possible for farming cooperatives. It goes without saying that the implementation of MFS requires extended technological features, such as sophisticated equipment, extended monitoring range, real-time processing capabilities and specialized artificial intelligence (AI) models.

Although precision agriculture is characterized by high complexity and depends heavily on cutting edge technologies, it constitutes a method that soon or later is going be used across the globe. Developed countries, such as USA, Australia, Canada and some European countries, including Germany, Finland, Sweden and Denmark, have made significant progress towards this area and already show some level of adoption of precision agriculture [36]. In developing countries instead, the acquisition of cutting edge technologies and the lack of suitable infrastructure constitute major impediments to precision agriculture exploitation. Although precision agriculture, as it can be found in North America, Australia and Europe, differs considerably in developing countries, the need for accurate data and targeted interventions is actually greater there, due to the stronger imperative for change and the lack of resources [37]. What is really encouraging is that over the past few years there has been considerable effort from developing countries to use some kinds of precision agriculture methods in various applications, such as yield monitoring and tractor auto guidance [36].

In developing countries, MFS play an important role, as in some cases they act as the backbone of a sustainable agricultural policy, especially for individual farmers or small farming communities [38]. During the last decades, research efforts in various developing countries have been redirected to integrated farming systems rather than dedicated ones, so as to cover several complementary enterprises under various agroecological situations [39-41]. These efforts revealed that integrated farming systems can not only be profitable and productive but also eco-friendly, a countermeasure to unemployment and provide financial stability to the stakeholders [42].

Designing and applying integrated farming systems has severe constraints. Towards the technological direction, a severe constraint is the lack of long-term, structured, concrete data [43]. In the best scenarios so far, end users' actions heavily depend on short-term, biased data. As a result, data analytic services fail to operate on a larger scale since they are highly affected by area peculiarities and seasonality [44]. That explains the fact that different frameworks and assessment schemes result in contradictory outcomes. Examining MFS implementations in view of the end-user, a new kind of barrier that lies in farmers willingness to cooperate, emerges. This barrier goes beyond technical solutions, adding a socio-economic dimension to the widespread exploitation of MFS.

MiFarm-CSA architecture aims at providing a CSA-based, multi-actor and communityoriented architecture, for advancing the current farming system to a smart, resilient and integrated/mixed farming ecosystem, aiming at increasing the resilience of the underlying farms, crops, livestock and forestry against the negative impacts of the climate change. Moreover, the proposed architecture envisions to foster cooperation between farmers and breeders through the provision of a sustainable MFS reference model. 
The remaining paper is organized as follows: Section 2 highlights the current state-ofthe-art. Section 3 presents the MiFarm-CSA architecture thoroughly; it illustrates the four layers of the architecture and delves into them in each of the subsections. Section 4 outlines the benefits of the proposed architecture. In Section 5 the conclusions are summarized.

\section{Related Work}

Current section reflects the current state of the art in integrated agricultural systems from technological, economic and social perspectives. It also points out current weaknesses that tend to be exacerbated due to the high complexity of a MFS.

\subsection{Data Aggregation Systems}

Improving mixed farm productivity is essential for increasing farm profitability and meeting the rapidly growing demand for food that is fueled by rapid population growth across the world and decreasing demand for energy. Mixed-farm productivity can be increased by understanding and forecasting crop and livestock performance in a variety of environmental, social and ecological conditions. Both crop and livestock recommendations are currently based on data collected in field-based agricultural studies that capture performance under a variety of conditions (e.g., soil quality, diseases, environmental conditions, etc.). The quality of manually collected performance data is very low, because it does not take into account earlier conditions that have not been observed by the human operators, but it is essential to filter out collected data that will lead to invalid conclusions. Furthermore, due to MFS, we must increase the volume of data, the number of the sources and the energy demands for efficient communication, consequently increasing the complexity of the data gathering process exponentially. To this end, the utilization of emerging technologies such as IoT devices, ground sensors, livestock sensors (collars/ear-tags), multispectral cameras and UAVs for data gathering purposes, is quite mature nowadays, and they can be used to collate vast amounts of environmental and crop-livestock performance data, ranging from time series data from sensors, to spatial data from cameras, to human observations collected and recorded via smart applications [45]. More specifically, their benefits are extended in the whole spectrum of the agricultural ecosystem. Their deployment decreases the farmer's labor tasks, facilitating his daily routine and making resource allocation more efficient. Moreover, the quality and quantity of data are improving and being enriched respectively, providing insights that enhance productivity while sustainable and eco-friendly processes are identified and fostered. Precision agriculture and data analytics are reshaping industry and market boundaries and interactions, with precision agriculture technologies (data holding, data specialization, data strategy) being a combination of: Global Positioning System (GPS), sensors mounted on farm machines or standalone, geo-mapping, automatics steering systems, electronic communications and variable rate technologies [46]. Increasing UAVs' obligations results in a higher energy consumption, a fact that could disrupt the sustainability and eventually the viability of the system [47]. Intelligent devices are deployed to collect specialized data and provide valuable information. Such devices are photonics which are utilized for monitoring and predicting the ripening process and quality of produce, ear-tags that gather information about animals' nutrition and multi-spectral cameras that collect images in different spectrums. The incorporation of such devices intensifies data diversity, raising concerns about interoperability between the physical components, data processing and information integration capabilities [48]. Obviously, these new trends on the one hand manage to handle some of the MFS concerns, but on the other hand reveal new challenges that need to be addressed.

\subsection{Socio-Technical and Socio-Economic Modeling}

Modeling and simulation tools can help in identifying opportunities for improved resource management, crop production and farm system sustainability. Modeling tools may also be used to predict the longer-term effects of suggested interventions and technologies and to enhance the understanding of their impacts [49]. One such tool developed in the 
context of African smallholder farmers is the integrated crop-livestock model NUANCESFARMSIM [50]. Agricultural Production Systems Simulator (APSIM) is the most used simulator for agriculture proposes. Since 1990, it has grown from a field-focused farming systems framework used by a small number of people, into a large collection of models used by thousands of modelers internationally. In this vein, APSIM Initiative is developing the next generation of APSIM [51].

FRAM and STAMP represent the current state-of-the-art for socio-technical modeling [52]. Both are deliberately lacking theoretical background about socio-technical system dynamics. Thus, the structure of modeling and inquiry is retrospective [53-55]. They are hindered in their utility and applicability by this theoretical vacuum. New methods are needed which are situated in a well-considered and thought-out theoretical landscape and which are based on evidence [56,57].

Recent literature suggests that understanding and considering the role of behavioral factors in farmers' adoption of sustainable practices can help enrich the traditional economic analysis of farmers' decision-making [58]. Within this literature, there is a burgeoning stream investigating the role of behavioral factors. Pre-testing the impacts of these behavioral factors on farmers' decision making can, in turn, lead to more effective agro-environmental policies, a crucial challenge in view of the enhanced environmental and climate ambitions for the future Common Agricultural Policy [59,60].

Moreover, economic experiments can be used effectively to improve the design and implementation of agriculture policy and programs. Recent developments have raised confidence in experiments as a useful tool for economic and policy analysis [61,62]. Beyond their role in reshaping how economic research is conducted, social science experiments have been used extensively to influence the designs of both markets and public policies [63-65]. Observation of behavior in a lab is convenient and affords a high degree of control over the environment, but the contexts of the laboratory and the participants are in many ways dissimilar to those in naturally occurring environments $[66,67]$.

\subsection{MFS Integration Analysis and Evaluation}

MFS are considered efficient designs for sustainable, ecologically-based farming systems. The sustainability of MFS relies on the complementarities between crops, livestock and forestry, and the exchange of resources within them. Not many studies are available from the last years in integrated systems, especially those involving all sectors of crops, livestock and forestry together. Two use cases were presented in [68], involving crops, animals and grasslands in France and Brazil. In [69] is an integration of crops and livestock approach, which helps farmers to develop a broader understanding of systemic interactions between crop and livestock activities on their farms. In [70] the authors presented a comprehensive assessment of all integrated systems identified in Mato Grosso by 2012/13. Despite the benefits associated with MFS, little is known about these systems or the challenges of implementing them, and only a limited number of farmers have adopted them so far.

\subsection{Knowledge-Based Management System in Agriculture}

Although some work exists in knowledge-based management and information systems in the agricultural domain, none of it corresponds to Mixed Farming Systems. GECO is presented in [71], which allows users formalize knowledge in a collaborative manner and to make it available to a large community. In [72] the authors propose a knowledge-based management system for exchanging and creating knowledge in organic farming. SmartAKIS [73] is a European network mainstreaming smart farming technologies among the European farmer community, aiming to bridge the gap between practitioners and research on the identification and delivery of new smart farming solutions to fit the farmers' needs.

\subsection{MFS Services}

Despite the renewed interest in MFS, these systems are facing a number of barriers and are still declining worldwide, representing about $14 \%$ of agricultural systems all over 
the world. The level of specialization depends on economic context, labor availability and pedo-climatic conditions. Despite their theoretical sustainability performance, MFS have been disappearing at the farm level. This could be partly explained by their low economic performance and social (work) constraints. First of all, MFS are not achieving equally good economic results to specialized farms. According to Farm Accountancy Data Network (FADN) [74] data, the average productivity of mixed farms, in terms of output/input economic value ratio, is comparable to the productivity of all European farms. The efficiency in input is comparable between mixed farming and all types of farms. Still, the income per worker in mixed farms remained below the EU-27 average. Moreover, direct payments represent a substantial part of farm net value added for grazing livestock, and mixed and field crop farms, due to their average farm size and the historical orientations of the Common Agricultural Policy (CAP) [75].

\subsection{Decision Support Systems in Agriculture}

DSS tools are divided into four categories in terms of applications: animals and animal products, land water and environment, crop and agribusiness and markets. Examples of crop DSS are MyCrop, ROOTMAP, Yield Calculator and SPLAT. For management problems in farms, intelligent DSS in agriculture have been introduced to monitor and to assist farmers to make decisions in a timely manner. However, designing a DSS is quite complex and requires knowledge from various multidisciplinary areas. Adinarayana et al. [76] proposed an information, communication and dissemination system called GeoSense. The system was designed to help in decision making for precision farming. Other work by Tamayo et al. [77] implemented a DSS for fertilization, crop growth control and prediction of diseases. Only two types of sensors, temperature and humidity, were utilized in their system. Jiber, Harroud and karmouch [78] focused their study on designing a precision agricultural monitoring framework. However, this study was limited as it did not use test beds to evaluate the performance of their monitoring systems. Aiello, Giuseppe et al. [79] proposed a methodological approach using a majority rule and bioeconomy strategies that implements a decision fusion algorithm which allows one to make the decisions about the possible risk of pest disease on the basis of the information (dew point temperature, leaf temperature, etc.) collected from all sensors of the network. Grigera, Julian et al. [80] presented three different usability evaluations: a heuristic evaluation, a user test and an automated diagnosis, based on 244 farmers and advisors in UK, and concluded that the most influential factor is the "ease to use a DSS".

\section{MiFarm-CSA Architecture}

MFS is characterized by multiple instances of crops, livestock and forestry, which may be in small or large geographical areas. Currently, MFS is not characterized by intense use of information and communication technologies (ICT) and where it exists, it is only used separately per farm or livestock level. In addition, current approaches are either very simplistic, omitting important aspect of MFS, or rather complex, making them impossible to implement, which generate drawbacks in management and at the economical level that prevent farmers from adopting MFS. MiFarm-CSA envisions to constitute an overall architecture that facilitates data exchange and integration in one platform which is delivered to the end users as a service, supporting several ICT deployments in crops, livestock and forestry, regardless of their geographical location. This approach is aiming to leverage MFS and improve in economic, social and environmental indicators. Figure 1 illustrates the MiFarm-CSA view of MFS against the current state.

The proposed architecture follows a layered approach since it offers a lot of benefits in comparison with a non-layered one. These benefits are summarized below:

- Easier to understand: architecture will be easier to understand, not only for the architects who designed it, but also for the technicians who are going to build and maintain it and for the people who are going to participate in it. 
- Easier to test: having a layered architecture makes it possible to define independent components much better, which makes component testing easier.

- Easier to extend: adding new features or changing current ones is easier in a layered architecture.
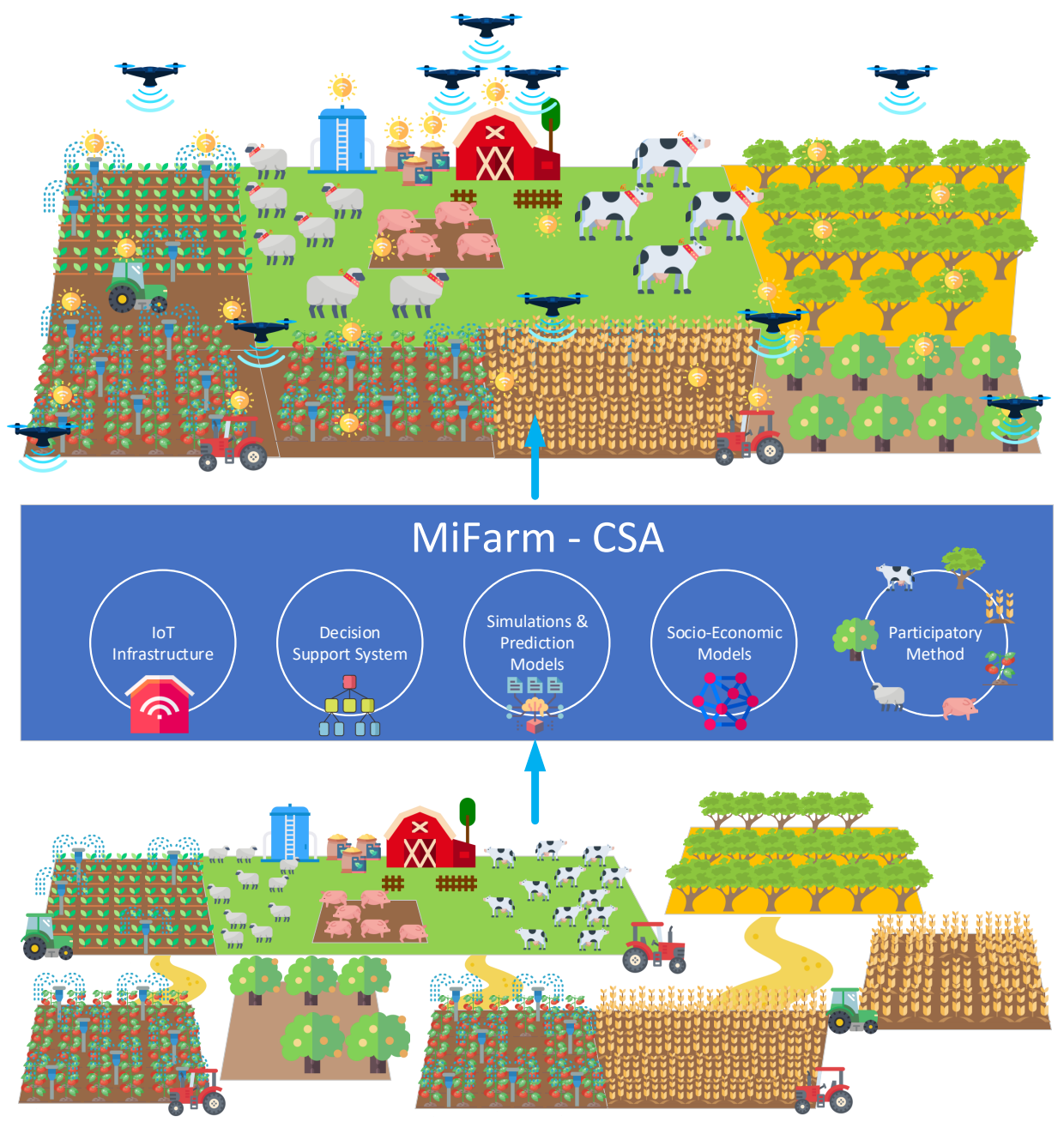

Figure 1. MiFarm-CSA concept.

In particular, the proposed architecture consists of four main layers:

Integrated Data Collection Network: In detail, the Integrated Data Collection Network (IDCON) applies to the area of MFS, to monitor any type of crops; livestock and forestry; and climate and soil parameters. More specifically, this tier exploits a wide range of Internet of Things (IoT) sensors, devices, gateways and servers, UAVs and FANETs, which are capable of covering large-scale areas for providing big volumes of data in near real time, such as information about the temperature, humidity, pressure, wind speed, $\mathrm{pH}$, dissolved oxygen levels, temperature, conductivity, etc. IDCON encloses four main tools, namely, the data capturing and recording system, which includes the smart sensing and tracking sensors, the aerial sensing systems and the weather and climate control systems; the energy management and harvesting system (EMHS); the semantic middleware and gateways (SMG); and cloud-based event and data analytics (CEDA) which includes the livestock farm management system and the cloud application.

The Social-Ecological Conceptual Framework: The second layer concerns the MiFarmCSA Social-Ecological Conceptual Framework (SECF) which aims to support sophisticated capabilities such as integrated farming to yield forecasts, and optimization of crop management in terms of fertilization, irrigation and sowing density, while at the same time 
providing social learning modules, in a user-friendly way, thinking skills, virtual scenarios, case studies and long-term predictions, estimations and business-oriented best practices based on the input received from the underlying MiFarm-CSA IDCON layer.

The Mixed Farming as a Service: The top layer of the architecture is the Mixed Farming as a Service (MFaS) which provides a set of advanced and efficient user applications and services destined to farmers and stakeholders. More specifically, the MFaS encloses eight main applications, namely: Resource Managers (ReMa), Integrated Irrigation and Fertilization Application (IFRA), Anomaly and Pest Detection Tool (APED), Novel Climate Service and Application (NCSA), Digital Market Radar (DiMaRa), Web-based Knowledge Exchange Service (W-KES) and Integrated Farming Systems Economics (IFSEC).

Evidence-based Assessment Methodology: The last layer concerns the MiFarm-CSA Evidence-based Assessment Methodology (EVAM), which serves as an horizontal layer that covers all the other layers, as the socio-economic aspects should be taken into account during all steps of the development of MFS. EVAM layer includes the SCOPE methodology for examining and creating dynamic process maps focusing on process functionality, social cohesion and the mediation of collective knowledge and information cycles. A further element of this approach is the social license to operate (SLO) concept. This concept relates to the continued acceptance of a set of business practices or operating procedures by a company's employees, stakeholders and the general public. In addition, in this layer the behavioral decision-making is also taken into account as it is a method to influence the farmers to adopt environmentally suitable practices.

Table 1, provides brief definitions of the concepts, technologies and practices used in MiFarm-CSA architecture.

\subsection{Integrated Data Collection Network}

The provision of an advanced data collection network and autonomous monitoring is a major pillar of MiFarm-CSA, which is realized by the IDCON. Figure 2 illustrates IDCON, which aims at designing and deploying the technology means that will allow MiFarm-CSA to measure data from different farming systems, e.g., forests, crops and livestock, and to expand the capability of the MFS in rough and slope terrains and in large-scale lands. IDCON encloses six cutting-edge technology solutions, systems, devices and gateways: (a) Smart Sensing and Tracking (SST), (b) Aerial Sensing System and Monitoring (ASSM), (c) Weather and Climate Control and Forecasting (WCCF), (d) EMHS, (e) SMG and (f) CEDA.

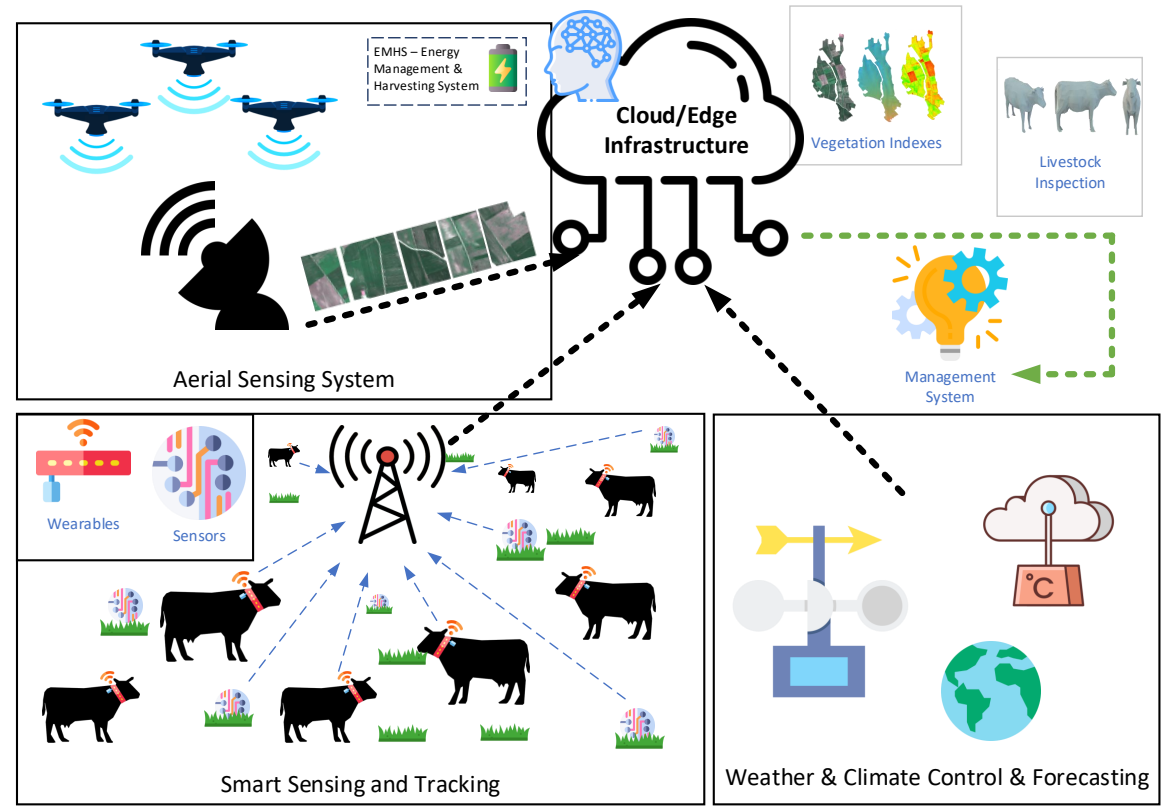

Figure 2. The IDCON layer of MiFarm-CSA architecture. 
Table 1. Definitions of concepts, technologies and practices.

\begin{tabular}{|c|c|}
\hline Concept-Technology & Definition \\
\hline Climate Smart Agriculture & $\begin{array}{l}\text { Agriculture that boosts productivity, enhances resilience, minimises } \\
\text { greenhouse gas emissions, and facilitates achievement } \\
\text { of national and international food security and development goals }\end{array}$ \\
\hline Integrated Farming Systems & $\begin{array}{l}\text { A biologically integrated system, which integrates natural resources } \\
\text { in a regulated mechanism into farming activities to achieve maximum } \\
\text { replacement of off-farm inputs and sustain farm income. }\end{array}$ \\
\hline Mixed Farming Systems & $\begin{array}{l}\text { A type of farming which involves crop cultivation and livestock rearing } \\
\text { together in an integrated form that is } \\
\text { managed as a single farming system. }\end{array}$ \\
\hline Precision Agriculture & $\begin{array}{l}\text { A farming management concept based on observing, } \\
\text { measuring and responding to inter and intra-field variability in crops, } \\
\text { aiming to lay down a decision support system for the whole farm management } \\
\text { with the goal of optimizing yield while preserving resources. }\end{array}$ \\
\hline "hicle & An aircraft without a human pilot on board. \\
\hline Internet of Things & $\begin{array}{l}\text { A network of physical objects, "things", that are embedded with sensors, } \\
\text { software, and other technologies for the purpose of connecting } \\
\text { and exchanging data with other devices and systems over the Internet }\end{array}$ \\
\hline Flying Ad-Hoc Network & $\begin{array}{l}\text { An Ad-Hoc network structure which is formed by } \\
\text { a set of UAVs of which at least one must be connected to a ground } \\
\text { control station or satellite }\end{array}$ \\
\hline Radio-frequency Identification & $\begin{array}{l}\text { A technology that uses electromagnetic fields } \\
\text { to automatically identify and track tags attached to objects. }\end{array}$ \\
\hline Machine Learning & $\begin{array}{c}\text { An application of artificial intelligence (AI) that provides } \\
\text { systems the ability to automatically learn and improve from experience } \\
\text { without being explicitly programmed. }\end{array}$ \\
\hline Low-Power Wide-Area Network & $\begin{array}{c}\text { A type of wireless telecommunication wide area network designed to allow } \\
\text { long-range communications at a low bit rate among things, } \\
\text { such as sensors operated on a battery. }\end{array}$ \\
\hline Geographic Information System & $\begin{array}{l}\text { A conceptualized framework that provides the } \\
\text { ability to capture and analyze spatial and geographic data. }\end{array}$ \\
\hline
\end{tabular}

Initially, the data capturing and recording takes place by using the SST, ASSM and WCCF. SST includes electronic sensors (passive and active wireless sensor devices) for environmental monitoring (quality of water, soil, air and nutrition concentration), phytoelectronic sensors for measuring environmental and soil changes via metabolic changes in plants (e.g., pH level and phytohormones) and soil-derived GHG emissions sensors that measure the effects of regenerative grazing regime and mixed farming practices on GHG losses. In addition, low-cost IoT-enabled GHG sensors are utilized for measuring the effects of emissions on local and regional levels. Since animal tracking is of paramount importance in any MFS, specialized IoT devices (e.g., collars and ear-tags) are also utilized for locating, monitoring and managing livestock. Beyond the conventional information such as (i) location, (ii) motion, (iii) temperature and (iv) animal behavior, collars and ear-tags can show (i) the areas of the farm that have been most frequently occupied and (ii) the history of the areas where the animals have been grazing. As a result, MiFarm-CSA architecture is able to boost feed efficiency, increase food quality, mitigate risks regarding the animal loss, decrease the stakeholder's expenses and increase his income.

Since the beginning of the development of new generations of UAVs, these platforms were considered a well suited tool, under different configurations, in agriculture, livestock and forestry because of their potential (size, weight, flight speed and altitude) [81]. ASSM provides a sophisticated technology by deploying single UAVs or groups of UAVs (FANETs) for implementing several monitoring and surveillance activities in the crops, livestock and 
forests [82]. The UAVs can be equipped with (i) multispectral sensors, (ii) hyperspectral sensors, (iii) thermal sensors, (iv) cameras and (v) GPS. The information is gathered by scanning crops, livestock and forest landscapes. In particular, by scanning the crops, ASSM will acquire (i) soil and field analysis, (ii) crop monitoring, (iii) yield estimation (iv) bidirectional reflectance properties of plant surfaces, $(\mathrm{v})$ health of plants (leaf area index, chlorophyll content, water stress detection, photosynthesis soil analysis) and (vi) soil composition in agricultural fields to estimate crop yields based on the computation of vegetation indices in farmlands [83]. By scanning livestock, ASSM will be able to gather information related to (i) counting animals; (ii) locations of animals; (iii) animal temperature; (iv) body condition scoring; (v) number of newly born animals; (vi) disease detection and animal identification using radio frequency identification (RFID). Lastly, ASSM will be capable of monitoring forests in terms of (i) carbon sequestration, (ii) tree canopy analysis, (iii) conservation features, (iv) monitoring biodiversity, (v) ecological landscape features and (vi) plant and tree health. As a result, ASSM constitutes a powerful information gathering tool, which offers advanced, real-time data collection and measurements tool, while expanding the monitored landscape, thereby allowing the development of MFS in rough areas. ASSM is expected to contribute to the resilience increase through instant macroscopic data gathering which enhances decision making, while reducing the cost (labor cost and data acquiring) of current solutions, e.g., ground surveying. Furthermore, based on technological advances such as edge computing, the ASSM can incorporate on-board, real-time video analyzers which enable the autonomous and dynamic flight control of UAV according to the results of video surveillance output. As a result, the time needed for scanning an area will be highly reduced, allowing MiFarm-CSA to expand the scalability of the monitored landscape.

WCCF can further extend the information provided to the MFS by including satellite, meteorological and climate-related information. Satellite-derived measurements are essential inputs to monitor water management and agricultural production for improving regional food security [84]. Observations coming from near real-time satellites can be used to mitigate the adverse impacts of extreme events and promote climate resilience.

MiFarm-CSA architecure can benefit from energy harvesting techniques in the operation of SST to reduce the environmental impact of farming. The optimal "energy management" policy can be defined based on existing machine learning (ML) models and AI algorithms [85].

Considering data storage and transfer, middleware software and the necessary hardware gateways and actuators are needed for storing and forwarding the captured data. The SMG component provides the necessary middleware software and gateway infrastructure to support IDCON by gathering all kinds of information from different sources. The middleware should able to abstract the heterogeneity and complexity of the underlying hardware devices, appliances or unmanned vehicles (data transmission formats, manufacturer particular features, operating systems, etc.) and to provide inter-operability among sensors, robots and smart devices. Reliability in communications, real-time data distribution, automatic discovery of entities and quality of service (QoS) monitoring is guaranteed by the middleware itself.

The CEDA component provides the data collection and processing system that is carried through into distributed computing systems and clusters for real-time processing. To this end, robust data analytics, high performance computing, efficient data network management and cloud computing (CC) techniques are used [86]. More specifically, the main pillars are (i) the integration of data that originate from different sources via a common communication point, and (ii) the provision of suitable adaptive algorithms for effective, dynamic and autonomous decision-making. Taking into account the massive and heterogeneous characteristics of data, acquiring and processing all of it is inefficient in terms of communication cost, computing complexity and the utilization of data storage resources. For this reason, dimensionality reduction should provide a reduced version (sketch) of original data taking into account the specific characteristics of the data generated. 
The Panoptis platform consists of hardware add-ons (collars and ear-tags) and software modules that provide tools to livestock farmers so as to locate and monitor livestock. The platform allows one to generate many types of enclosures, sub-areas and points of interest. This allows one to have records and monitoring of animal behavior in these enclosures. The challenge in this component lies in the integration of information when received from different sources: (a) IoT devices mounted on animals; (b) satellite information about pastures; (c) weather forecast; (d) soil sensors, in a DSS to improve grazing management.

The interconnection between the data collecting and the data storing can be achieved through low power wide area networks (LPWAN) such as LoRA and Sigfox telecommunication networks. LoRa and Sigfox protocols are widely used for supporting smart applications and monitoring systems [87].

\subsection{Evidence-Based Assessment Methodology}

EVAM is defined as a major pillar of the proposed architecture, for fostering the involvement of end-users in the MFS landscape, consisting of the following components: (a) (SCOPE) methodology, (b) the SLO concept, (c) the behavioral decision-making (BDm) and (d) the Behavioral Intervention Engine (BIE).

Oftentimes in technology, development projects the social, behavioral and even human aspects of the technology play a secondary role to the technological aspects. The proposed architecture intends to use innovative human factor approaches and methodologies to champion social and behavioral aspects and to prioritize the role of the human in the development of technology. Doing so will ensure that the implementation will not encounter barriers relating to user acceptance, usability and other human barriers. The starting point involves refining new methods for modeling the socio-technical aspects of farming systems and to examine the social and behavioral aspects of mixed farming and agroforestry. The SCOPE methodology examines and creates dynamic process maps focusing on three interlocking and interdependent levels of analysis: (i) process functionality (operational processes); (ii) social cohesion (trust and social networks); and (iii) the mediation of (i) and (ii) through collective knowledge and information cycles [88].

A further element of this layer is the SLO concept. This concept relates to the continued acceptance of a set of business practices or operating procedures by a company's employees, stakeholders and the general public. The concept of social license is closely related to the concept of resilience and sustainability, and the work to define and develop the SLO in this architecture will ensure that the technical innovations can be supported by sustained social and behavioral change.

According to many MFS experts, the problems of the end users, mostly farmers, are not just about knowledge: it is about building the habit of cooperating. Over the last few decades, researchers have increasingly studied the factors that influence farmers' adoption of environmentally sustainable practices [89]. Previous academic attempts to take stock of the factors influencing farmers' adoption of sustainable practices [90] did not specifically focus on the roles of behavioral factors, often resulting in an incomplete overview and limited theoretical understanding of how and why these factors affect decision-making. There have been some efforts in policy circles to make an inventory of behavioral factors influencing farmers' adoption of sustainable practices, but their disciplinary scope was restricted to behavioral economics and communication sciences [91]. For this reason, MiFarm-CSA architecture introduces BDm which adopts the experimental research concept combined with laboratory experiments in parallel. The innovation of this concept lies in the following twofold statement: (a) it evaluates ex-ante farmers' choices when they are faced with voluntary versus mandatory schemes and with results based or collective schemes, and (b) it includes experiments in the field, which are carried out to inform agricultural policies by including a behavioral component, as the outcome variable generally consists of decisions made by farmers [92,93]. To take a positive step forward, the proposed architecture is built on top of BDm the BIE. The latter aims at: (a) predicting the expected MFS-related behavior (behavioral intentions) of farmers on the basis of a 
set of socio-economic factors, (b) facilitating the selection and application of appropriate strategies through a number of communication tools and channels and (c) driving the desired MFS development widely. The main operating elements of the BIE break down as follows: farmers can be clustered according to their (socio-demographic) profiles, and the suitability of involvement strategies is defined both by the user profile and by additional socio-economic factors (e.g., country culture). The resulting model will be used by the MiFarm-CSA decision support system.

\subsection{The Social-Ecological Conceptual Framework}

The lessons learnt and the experience of farmers stemming from the existing MFS are of paramount importance for further development of MFS. The production of more knowledge on MFS and the knowledge acquisition by farmers are both required in order to develop sustainable, productive, viable and efficient future MFS. The SECF component of MiFarm-CSA architecture aims to foster core interactions among animals, forests and crops, while mitigating the high complexity of these interactions. SECF follows a participatory, learning and technology-oriented methodological approach based on knowledge-driven tools. This methodological approach is defined in five main pillars, namely, (a) the participatory knowledge building (PKB), (b) the mixed farming simulator (MFSim), (c) the experimentally-oriented co-design process (EC-P), (d) the peer learning network (PLN) and (e) decision-making engine (D-ME).

$\mathrm{PKB}$ involves the critical knowledge extraction, which encloses the most important knowledge needed to support sustainable MFS. This knowledge can be extracted from meetings, seminars and workshops and recent literature findings. The contributions of international experts who will analyze and evaluate the current knowledge and remaining uncertainties about large-scale, commercial MFS are crucial. The PLN pillar encourages technical and organizational innovation; it enhances learning options, while reducing the isolated position of this kind of system in a specialized world. The PLN could address MFS, by (a) identifying learning issues, (b) supporting the exchange of (tacit) knowledge within the network and (c) organizing access to relevant sources of knowledge outside the peer network. The final step of the PKB is related to the knowledge-exchange beyond the PLN. The PLN ensures knowledge exchange among peers; e.g., it could also be valuable that experienced farmers and stakeholders organize access for other actors (advisors, research and policy makers) who are interested in MFS. Field visits, thematic networks and technological demonstrations constitute an immersive type of learning which can enhance significantly the process of knowledge exchange.

The participatory knowledge building can be enriched with state-of-the-art technologies like virtual and augmented reality. Such technology could maximize the participants' engagement in the training material, by fostering the motivation of end users to be engaged to the PKB and the SECF activities in general.

The MFSim is also introduced as another major pillar of SECF in order to mitigate the complexity of MFS. Recent trends in broader collaboration across institutions, across disciplines and between the public and private sectors suggest that the stage is set for the major advances in agricultural systems science that are needed for the next generation of models, databases, knowledge products and decision support systems [49,94]. Specialized simulation modeling of crop-livestock integration among farms is the basis for achieving the up-scaling process involved in integrating beyond the farm level. Furthermore, computer simulation with environmental-economic models at the farm level provide a useful tool for integrating knowledge and information to predict production efficiency, environmental impacts and the effects of management policies on production performance [95]. The MFSim is introduced as the main modeling and simulation tool of designing, testing, validating and evaluating mixed farming modeling systems and complex simulation scenarios. The aim of MFSim lies in the fact that it allows farmers, stakeholders and supply chain actors to experiment with diversified cropping, animal and forest systems without having to invest or risk resources. MFSim could also enable stakeholders to (a) model 
and simulate different variations of forest-crop-livestock integrated farms, (b) model and simulate different use of resources (nutrients, land, manure management, etc.) and (c) model and simulate manure management practices and animal feeding. In particular, MFSim could provide significant insights in (a) simulating livestock performance, while grazing grain crops, (b) assessing diversifying crop rotations in terms of sale and animal feeding sources, (c) studying and evaluating tactical and strategic responses to improve the performance of livestock feed systems, (d) modeling and evaluating the implications of grazing crops on the livestock system as a whole, (e) analyzing and evaluating the production and economic risk mitigation benefits that arise from operating a mix of crop and livestock systems, (f) evaluating recycling tactics in animal manure to fertilize crops and $(\mathrm{g})$ simulating the integration of alternate crops in the crop rotations.

The EC-P is also introduced as a component of SECF, as its aim is to motivate farmers to cooperate in the knowledge exchange processes without feeling loss of freedom and independence [96,97]. The EC-P engages farmers in laboratory and field experiments, by conducting trials and demonstrations together with the experts. In particular, during laboratory experiments, the stakeholders and the researchers can work together and see how the technology will be used in practice.

\subsection{Mixed Farming as a Service}

The MFaS is the fourth main pillar of MiFarm-CSA whose aim is to deliver a rich suite of tools and services to the end users (farmers, agricultural companies, decision makers, regulators, supply chain actors, stakeholders and individuals) in three dimensions, namely, (a) environmental, (b) economic and (c) social. MFaS goes beyond than a conventional toolkit for farmers; it constitutes the main decision support system of the proposed architecture. MFaS serves as an integrated management software that helps farmers and growers to establish sustainable farm management practices and reach profitable crop production, by enclosing various applications and services related to conventional farming systems. The envisioned MFaS should support the following MFS applications and services: (a) the Integrated Farming Systems Economics (IFSEC), (b) the W-KES, (c) the APED, (d) the Integrated Irrigation and Fertilization Application (IIFA), (e) the NCSA, (f) the Resource Managers (ReMa) and (g) the DiMaRa.

IFSEC is a critical component of MFaS, as it provides the decision-making component of the proposed architecture. IFSEC analyses existing case-studies of well-managed MFS; develops a labor-balanced analysis based on farm surveys; develops participative approaches with groups of farmers to consider their management strategies and develop scenarios; and identifies management tools to assess MFS labor requirements and associated costs so as to facilitate integration between farms. In particular, IFSEC should abe considered as completed when it is in such position to provide (a) advanced logistics, (b) advanced financial management, (c) MFS management and (d) MFS visualizations. The IFSEC advanced logistics could include (i) labor management, (ii) machinery management and (iii) inventory management. In general, the end user should be able to register a farm by adding financial information, work task assignment per worker and cost per worker. Additionally, economic features for machinery can be included, i.e., cost per individual category task per hour or area unit. Reservation for a machine for specific hours and inventory management could be available as well. The IFSEC advanced financial management could include the management of (i) sales, (ii) expenses, (iii) assets, (iv) loans, (v) budget and (vi) transactions. The end user should be able to register sales invoices containing multiple items, while the corresponding quantity per item will automatically stored to the defined warehouse. The IFSEC MFS management could involve: (i) crop-livestock diversification per individual field; (ii) week, month, year and long-term forecasting, including temperature, wind speed and rainfall $(\mathrm{mm})$. Information for pests, weeds and diseases with detailed descriptions and a list with active substances which fight or prevent them could be included as well. The IFSEC MFS visualizations will bring new dashboards with real-time data with predefined templates like usage, productivity, finances, Key Perfor- 
mance Indicators (KPIs) and field analytics, while the MiFarm-CSA engine will be featured to export a structured report in a user-friendly manner, such as tasks, crop production, usage, finances, cost per task, inventory and resources.

The W-KES applies a collaborative service to share knowledge, experiences and innovations among the different people involved in the design and application of MFS agricultural systems. W-KES is composed by three components: (a) the W-KES semantic model, (b) the W-KES web-based application and (c) W-KES forum. The semantic model is organized in a set of triplets, "subject", "predicate" and "object" [98], and the triplets are interconnected. The main resources of the W-KES semantic model are (a) web pages created in a collaborative manner, (b) simulation results conducted by the MFSim, (c) best practices formed as documents, stemming from the SECF and (d) educational material and training modules coming from the PLN. These resources are associated with certain triplets; for example, users can associate the triplet "wheat", as "can be attacked by": "aphids" in a web page presenting knowledge about wheat. Furthermore, the W-KES intends to include a knowledge search service, which allows users to query web pages by keyword, string or sentence matching. For example, a user may search for manure quality management for MFS and the W-KES web-based application will propose related web pages, material content from the PLN and best practices-extracted from the SECF layer. Lastly, the W-KES web-based application incorporates a forum, which allows any user to share his opinion; or ask the community about information or a new topic that he cannot find in another source. The innovation behind this service lies in the fact that it can also enable direct and indirect exchange of resources like feed and manure.

Based on the information collected by the IDCON, The APED and the IIFA are envisaged as smart services for in-field operations and data analysis. According to the characteristics of plant pathogens, efficient plant disease management requires a high density of spatial and temporal information regarding the condition of any parameter related to the crop growth [99]. Hyperspectral images combined with ground sensors can identify host-pathogen interactions at an early stage. This fact can simplify the complexity of the identification and the quantification of different kinds of stress factors that may result in crop anomalies [100]. Moreover, data mining techniques [101] (ML methods like artificial neural networks or support vector machines (SVM)) can be leveraged since they have proved to be superior for distinguishing in between more than one type of stress factors and different diseases [102]. The integration of ground sensor data provided by SST and image data provided by ASSM in combination with Geographic Information Systems (GIS) and data mining techniques will constitute the core of APED services. IIFA services besides the integration between ground sensor data provided by SST and image data provided by ASSM will also incorporate data from WCCF. This holistic integration of drought-causative information (precipitation) and drought-responsive information (vegetation condition, crop anomaly) aim to develop specialized variations of well known vegetation indexes (e.g., normalized difference vegetation index) (i) for superior drought monitoring and (ii) for early indication of any decrease in crop production associated with drought or lack of nutrients [103].

A dashboard will be the human-machine interface for delivering the information coming from the WCCF, and to make suggestions and recommendations based on the captured satellite, meteorological and climate-related information. Concurrently, the dashboard could also digest the information stemming from the meteorological stations, which are installed at the field, in order to provide short-term predictions and suggestions.

Recent political priorities in Europe aim to rationalize agricultural production, reduce pollution, upgrade the environment, maintain rural infrastructures and meet new societal concerns, such as product quality and animal welfare. For example, soil testing has been proven to be a valuable tool for evaluating the available nutrient status of soil. The soil investigation is exceptionally useful for cultivators to discover which sort of harvests to be developed in a specific soil condition and helps to determine the proper amount of nutrients to be added to a given soil based on its fertility and crop needs. The intensification 
of livestock operations in the last few decades has resulted in increased social concern over the environmental impacts of livestock operations, and thus making appropriate manure management decisions is increasingly important. Animal manure is a valuable resource if handled responsibly but a source of serious challenges and public health concerns if managed inappropriately. Risks associated with animal manure handling could be related to soil, water and air quality. A socially acceptable manure management system that simultaneously achieves the pressing environmental objectives while balancing the socio-economic welfare of farmers and society at large is needed. Manure management decisions involve a number of decision makers with different and conflicting views of what is acceptable in the context of sustainable development. In order to ensure that the proposed schema is complete, this kind of resource management can not be ignored. For this reason, MiFarm-CSA introduces ReMA includes a series of resource managers to provide the optimal and accurate resource allocation:

- The Soil Manager (SOMA) aims provide optimal decisions, recommendations and case studies on how the soil quality will be maximized. While each of these decisions, recommendations and case studies represent possible techniques to effectively manage soil resources, each practice will be adequately assessed to identify possible constraints or drawbacks.

- The Manure Manager (MAMA) aims to provide optimal decisions, recommendations and case studies on the manure management in Mixed Farming Systems. The utilization of livestock manure to add nutrients back to the soil is one of the key croplivestock interactions in MFS. Manure when used as a soil amendment can benefit the soil, resulting in crop production and resilience benefits for smallholders via increased nutrient supply to crops and improved soil structure and water holding capacity. Manure has well-documented impacts on soil chemical and physical properties.

- The Water Manager (WAMA) will be able to make optimal decisions on the water management on the MFS. Improving water use efficiency and water management on mixed farms is arguably the most important and high potential improvement for farmers to be climate-smart. Optimal water management strategies increase net returns and purchasing power parity of households much more than any other and perhaps presents the only viable pathway to help transition smallholder farmers out of poverty.

Due to the withdrawal of market intervention policies, market volatility has increased, causing high income risk for specialized farms. Given that both global agricultural markets and agricultural policies enhanced efficiency in producing more of a same product, e.g., favouring economies of scale through intensification, enlargement and specialization, DiMaRa's goal is to assist MFS to have the flexibility to face uncertain climate and market conditions. As a service, the DiMaRa should be able to gather market-oriented data from several sources, while compiling it using big data analytics for transforming it to knowledge and recommendations. The purpose of DiMaRa lies in three axes:

- Aggregate accurate and timely climate and market information (weather, demand, supply and prices);

- Process and analyze it in a way such that it will be transformed into usable knowledge (intelligence) using big data analytics;

- Disseminate it to mixed farming stakeholders through web and mobile applications.

Data aggregation could encompass (i) data from WCCF, (ii) information about the prices of commodities which are directly or indirectly related to mixed farming ecosystems [104], (iii) data from Agriculture Market Information Services (AMIS), which constitute another source of interest with rich agriculture-related data [105] and (iv) data coming from Google marketing tools such as Google Trends and Google Keyword Tool, which will be utilized to capture near-real time data for trends in the field of agriculture.

Moreover, the complete MiFarm-CSA architecture with the four layers and their interconnections is illustrated in Figure 3. 


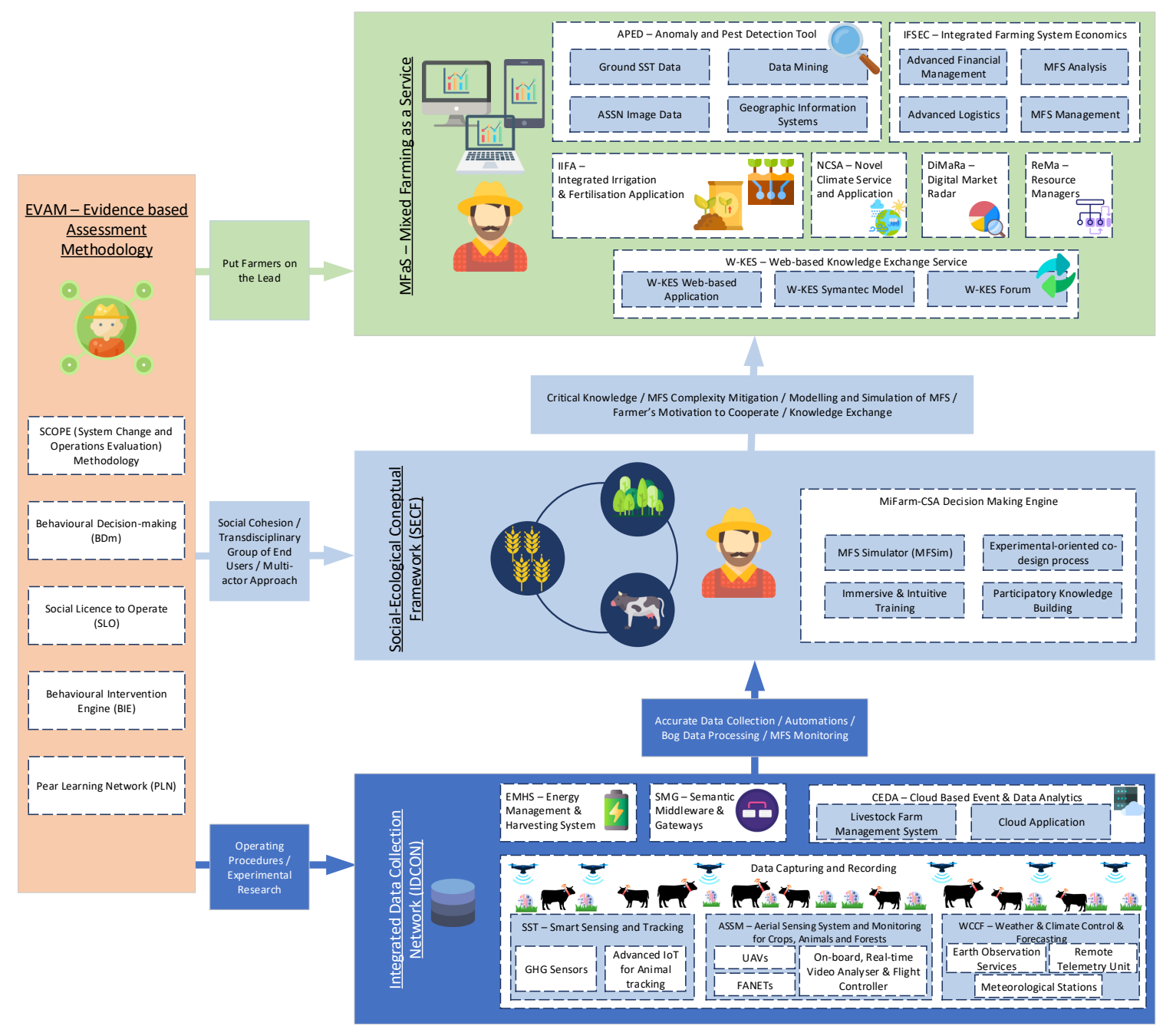

Figure 3. MiFarm-CSA Architecture.

\section{The Expected Benefits of Mifarm-CSA Architecture}

CSA addresses the challenges which climate change poses to agricultural production. MiFarm-CSA constitutes an efficient CSA-driven architecture which forms a user-oriented, social-aware and ecological platform, deployed as a service. Its main benefits are outlined as follows:

- Increasing agricultural productivity and income while also enhancing resilience or adaptation of livelihoods and ecosystems towards climate extremes. Through the IDCON, SECF and MFaS layers, the proposed architecture exploits multi-disciplinary, on-field and off-field data, to train the novel DSS, thereby enabling it to make optimal decisions, which are expected to boost MFS productivity and stakeholders' incomes. Moreover, through DiMaRa, MiFarm-CSA is anticipated to provide MFS the flexibility to face uncertain climate and market conditions.

- Increasing synergies among different farming systems by adopting new data collection and monitoring technologies, such as smart sensors, robots, UAVs, advanced tracking systems, long-range IoT-enabled sensors, middleware and gateways. The IDCON layer provides the cutting-edge technologies for applications in MFS: IoT sensors, devices, modern UAVs and FANETs, which aspire to be fully autonomous and multicollective, supporting, advanced processing and integration functionalities and are capable of covering large-scale areas for providing big volumes of data in near real time. The autonomy is twofold: the energy autonomy will be accomplished by 
deploying energy harvesting techniques for recharging sensors and UAVs and by defining a pilot-sensitive energy-budget approach for each data collection technology.

- Speeding up the establishment of a community of practice and dynamic methodology in designing, developing and evaluating mixed and integrated farming systems. MiFarm-CSA adopts innovative human factor approaches and methodologies to champion social and behavioral aspects and to prioritize the role of the human in the technological development. By exploiting SCOPE in the proposed architecture, the aim is to facilitate a comparison between the current ways in which mixed farming and agroforestry are conducted and future ways which better account for the sociotechnical system as described by SCOPE. This whole approach enables MiFarm-CSA to assess the inadequacies of the current treatment of social and behavioral issues and ensure that the emerged outcomes are built around the identified social and behavioral aspects of mixed farming and agroforestry. CoP will involve a multi-actor and trans-disciplinary group of end users. SLO relates to the continued acceptance of a set of business practices or operating procedures by a stakeholders. Moreover, SLO ensures that the technical innovations can be supported by sustained social and behavioral change.

- Forming a basis for the creation of a conceptual framework to analyze crop-livestock integration by fostering core interactions among animals, grasslands and crops, developing metabolic analysis of material flows, devising a biodiversity approach for the development of integrated crop-livestock systems and promoting social resources and stakeholder interactions.

- Prescribing a rich suite of user-friendly MFS applications and services for fostering the optimal combination of production, accurate climate change estimations and optimal decisions on local and national levels.

\section{Case Study}

The proposed architecture envisages upgrading, in terms of sustainability, areas where different agricultural systems, such as crops, livestock and forestry, coexist. For the purpose of the paper, a case study was considered in the area of the Western Macedonia, Greece for evaluating the components of MiFarm-CSA architecture.

The area of interest is located in a region of Western Macedonia in Greece, called Grevena. It is a mountainous area which is surrounded by a forest and includes a wide variety of flora, including fruit trees, grapevine, berries and vegetables. Nearby the forest, there is rich livestock activity by local farmers. The main challenges raised in this area are summarized as follows:

- Climate change has affected the biodiversity of the area, having negative impacts on the yield production and the soil quality.

- High operational and labor costs (energy needs, animal feeding) add a lot of pressure to farming businesses.

- The extensive use of chemical inputs (fertilizers and pesticides) has negatively affected the water cycle.

- The animal waste management is not sufficient, leading to negative environmental effects and waste of resources.

- The lack of forestry woodland management results in high risks of things such as wildfires.

- Low cooperation between local farming businesses due to a poor local market.

- A wide skill gap between each kind of system, deteriorating the objective of collaboration considerably.

- Technological deficiencies, as farmers are not aware of modern monitoring and surveillance methods to reduce their labor costs.

- Absence of local professional groups in MFS rules out the possibility of combining local agricultural and livestock practices. 
These challenges hinder the local farmers and stakeholders from further extending and utilizing their resources. In addition, farmers and stakeholders are quite skeptical towards changing - and therefore increasing their profits and sustainability - to a collaborative farming scheme such as MFS.

Within MiFarm-CSA, the cooperation between the forest, the local farms and the local stakeholders will be fostered by applying the EVAM methodology in integrating sustainable agriculture, livestock and forestry combinations. The rationale behind this lies in products' attractiveness (high nutritionally valuable products, longer shelf life of dairy products), Protected Designation of Origin (PDO) products and livestock welfare (animal immunological status enhancement and efficient animal breeding systems). Through the IDCON layer a variety of combinations of mixed farming solutions will be monitored, resulting in providing valuable data that can be further analyzed to reveal interesting correlations that would be impossible to discover otherwise. Moreover, MiFarm-CSA using SECF and MFaS, is expected to reduce the environmental footprint of the system, decrease input and management costs and increase the system's overall productivity. In detail, it is expected to contribute to the decrease of atmospheric $\mathrm{CO}_{2}$ pollution and to the mitigation of global warming, through the carbon sequestration process. In order to achieve it, the proposed architecture will exploit forestry and managed woodland in-between the cultivation and grazing lands and the livestock wastes so as to increase carbon sequestration. Moreover, an additional increase of the total volume of woodland biomass will further increase the carbon sequestration. Furthermore, weed management cost is expected to decrease with the use of animal grazing, which leads to a reduction of machine hours required as an indirect measurement of fossil fuel consumption, and the use of mulched woodland material can decrease the evaporation of soil water and consequently reduce the irrigation water volume. Last but not least, the animal waste usage in crop cultivation will increase its quality, decrease use of chemicals and also decrease transportation costs. Through SECF and MFaS, the mixed treatments will aim to rationalize agricultural production; reduce pollution and protect the environment; maintain rural infrastructure; and meet emerging social concerns, such as product quality and animal welfare. Besides the increases in animal feed supply and system productivity, which lead, on the one hand to income increase, and on the other hand to decreases in operational costs, a positive side-effect of this collaboration is that job opportunities are expected to increase, since more disciplines will be required to handle the system's complexity.

\section{Conclusions}

The food supply chain is a key strategic sector globally, from both economic and labor perspectives. This sector is also critical to meet the great societal challenges of sustainable farming, food security, food safety and healthy nutrition, now and in the future, which constitute without a doubt the most important priorities for both citizens and policy makers. Nevertheless, agriculture is at a crossroads on a global level. The increasing digitalization of agricultural practices makes it possible to produce plant and animal products with ever higher efficiency and ever lower environmental impact. Therefore, the agri-food sector is expected to become more and more data-driven by the use of ICT, while the need for AgTech-enabled innovation will become greater than ever. A number of technologies not traditionally used in the agri-food sector are now starting to play a key role in what is perceived as an AgTech revolution. Automation, artificial intelligence, drones, big data and cloud analytics offer us the opportunity to further our mastery of agriculture. The Industrial Revolution 4.0 is expected to generate disruptive changes in agricultural practices and pave the way for new innovative ideas that aspire to obtain market share from a billion dollar market. This ICT-revolution is expected to further advance and evolve smart farming/smart agriculture, including CSA and precision agriculture.

In this work, a multi-actor architecture introduced as a reference for the innovative concept of CSA was applied in integrated agricultural systems, such as MFS. The proposed architecture aims at providing a CSA-based, multi-actor and community-oriented architec- 
ture, enhanced with models, tools, frameworks and cutting-edge solutions, for advancing the current farming system to a smart, resilient and integrated/mixed farming ecosystem, aiming at increasing the resilience of the underlying farms, crops, livestock and forestry against the negative impacts of the climate change. The next step of this work is to conduct a qualitative and quantitative analysis of the performance of the proposed architecture in the two pilots, based on specific KPIs.

Author Contributions: Conceptualization, G.K. and P.S.; methodology, P.S. and T.L.; validation, P.S., K.Z. and C.K.; formal analysis, T.L.; investigation, A.M.; resources, C.K.; data curation, C.K.; writing-original draft preparation, G.K.; writing—review and editing, P.S.; visualization, G.K.; supervision, P.S.; project administration, T.L.; funding acquisition, P.S. All authors have read and agreed to the published version of the manuscript.

Funding: This research was funded by European Union's Horizon 2020 research and innovation programme under grant agreement number 957406 (TERMINET).

Informed Consent Statement: Informed consent was obtained from all subjects involved in the study.

Acknowledgments: This project has received funding from the European Union's Horizon 2020 research and innovation programme under grant agreement number 957406 (TERMINET).

Conflicts of Interest: The authors declare no conflict of interest. The funders had no role in the design of the study; in the collection, analyses or interpretation of data; in the writing of the manuscript; or in the decision to publish the results.

\section{References}

1. Goldstone, J.A. The new population bomb: The four megatrends that will change the world. Foreign Aff. $2010,89,31$.

2. Young, A. Is there really spare land? A critique of estimates of available cultivable land in developing countries. Environ. Dev. Sustain. 1999, 1, 3-18. [CrossRef]

3. Conforti, P. Looking Ahead in World Food and Agriculture: Perspectives to 2050; Food and Agriculture Organization of the United Nations (FAO): Rome, Italy, 2011.

4. Rojas-Downing, M.M.; Nejadhashemi, A.P.; Harrigan, T.; Woznicki, S.A. Climate change and livestock: Impacts, adaptation, and mitigation. Clim. Risk Manag. 2017, 16, 145-163. [CrossRef]

5. Lobell, D.B.; Sibley, A.; Ortiz-Monasterio, J.I. Extreme heat effects on wheat senescence in India. Nat. Clim. Chang. 2012, 2, 186-189. [CrossRef]

6. Prasanna, V. Impact of monsoon rainfall on the total foodgrain yield over India. J. Earth Syst. Sci. 2014, 123, 1129-1145. [CrossRef]

7. Brida, A.B.; Owiyo, T.; Sokona, Y. Loss and damage from the double blow of flood and drought in Mozambique. Int. J. Glob. Warm. 2013, 5, 514-531. [CrossRef]

8. Porter, J.R.; Xie, L.; Challinor, A.J.; Cochrane, K.; Howden, S.M.; Iqbal, M.M.; Lobell, D.B.; Travasso, M.I. Food Security and Food Production Systems; Cambridge University Press: Cambridge, UK, 2014.

9. Lipper, L.; Thornton, P.; Campbell, B.M.; Baedeker, T.; Braimoh, A.; Bwalya, M.; Caron, P.; Cattaneo, A.; Garrity, D.; Henry, K.; et al. Climate-smart agriculture for food security. Nat. Clim. Chang. 2014, 4, 1068-1072. [CrossRef]

10. Totin, E.; Segnon, A.C.; Schut, M.; Affognon, H.; Zougmoré, R.B.; Rosenstock, T.; Thornton, P.K. Institutional perspectives of climate-smart agriculture: A systematic literature review. Sustainability 2018, 10, 1990. [CrossRef]

11. Campbell, B.M.; Thornton, P.; Zougmoré, R.; Van Asten, P.; Lipper, L. Sustainable intensification: What is its role in climate smart agriculture? Curr. Opin. Environ. Sustain. 2014, 8, 39-43. [CrossRef]

12. Bai, X.; Huang, Y.; Ren, W.; Coyne, M.; Jacinthe, P.A.; Tao, B.; Hui, D.; Yang, J.; Matocha, C. Responses of soil carbon sequestration to climate-smart agriculture practices: A meta-analysis. Glob. Chang. Biol. 2019, 25, 2591-2606. [CrossRef]

13. Branca, G.; McCarthy, N.; Lipper, L.; Jolejole, M.C. Climate-smart agriculture: A synthesis of empirical evidence of food security and mitigation benefits from improved cropland management. Mitig. Clim. Chang. Agric. Ser. 2011, 3, 1-42.

14. Rosenstock, T.S.; Lamanna, C.; Namoi, N.; Arslan, A.; Richards, M. What is the evidence base for climate-smart agriculture in East and Southern Africa? A systematic map. In The Climate-Smart Agriculture Papers; Springer: Cham, Switzerland, $2019 ;$ pp. 141-151.

15. Dinesh, D.; Frid-Nielsen, S.; Norman, J.; Mutamba, M.; Loboguerrero, A.M.; Campbell, B.M. Is Climate-Smart Agriculture Effective? A Review of Selected Cases; Climate Change Agriculture Food Security (CCAFS): Copenhagen, Denmark, 2015.

16. Stein, S.; Steinmann, H.H. Identifying crop rotation practice by the typification of crop sequence patterns for arable farming systems-A case study from Central Europe. Eur. J. Agron. 2018, 92, 30-40. [CrossRef]

17. Kremen, C.; Iles, A.; Bacon, C. Diversified farming systems: An agroecological, systems-based alternative to modern industrial agriculture. Ecol. Soc. 2012, 17, 44. [CrossRef] 
18. Segnon, A.C.; Achigan-Dako, E.G.; Gaoue, O.G.; Ahanchédé, A. Farmer's knowledge and perception of diversified farming systems in sub-humid and semi-arid areas in Benin. Sustainability 2015, 7, 6573-6592. [CrossRef]

19. Kremen, C.; Miles, A. Ecosystem services in biologically diversified versus conventional farming systems: Benefits, externalities, and trade-offs. Ecol. Soc. 2012, 17, 40. [CrossRef]

20. Pervaiz, Z.H.; Iqbal, J.; Zhang, Q.; Chen, D.; Wei, H.; Saleem, M. Continuous cropping alters multiple biotic and abiotic indicators of soil health. Soil Syst. 2020, 4, 59. [CrossRef]

21. Scavo, A.; Mauromicale, G. Integrated Weed Management in Herbaceous Field Crops. Agronomy 2020, 10, 466. [CrossRef]

22. Krebs, J.; Bach, S. Permaculture-Scientific evidence of principles for the agroecological design of farming systems. Sustainability 2018, 10, 3218. [CrossRef]

23. Altieri, M.A.; Nicholls, C.I. An agroecological basis for designing diversified cropping systems in the tropics. J. Crop. Improv. 2004, 11, 81-103. [CrossRef]

24. Altieri, M.A.; Nicholls, C.I.; Montalba, R. Technological approaches to sustainable agriculture at a crossroads: an agroecological perspective. Sustainability 2017, 9, 349. [CrossRef]

25. Hafla, A.N.; MacAdam, J.W.; Soder, K.J. Sustainability of US organic beef and dairy production systems: Soil, plant and cattle interactions. Sustainability 2013, 5, 3009-3034. [CrossRef]

26. Farah, A.B.; Gómez-Ramos, A. Competitiveness vs. Sustainability: An Assessment of Profitability as a Component of an Approach on "Sustainable Competitiveness" in Extensive Farming Systems of Central Spain. Sustainability 2014, 6, 8029-8055. [CrossRef]

27. Gonzalez-Garcia, E.; Gourdine, J.L.; Alexandre, G.; Archimède, H.; Vaarst, M. The complex nature of zation requires multidimensional actions supported by integrative research and development efforts. Animal 2012, 6, 763-777. [CrossRef] [PubMed]

28. Manolis, J.C.; Chan, K.M.; Finkelstein, M.E.; Stephens, S.; Nelson, C.R.; Grant, J.B.; Dombeck, M.P. Leadership: A new frontier in conservation science. Conserv. Biol. 2009, 23, 879-886. [CrossRef] [PubMed]

29. McGuckian, N.; Rickards, L. The social dimensions of mixed farming systems. In Rainfed Farming Systems; Springer: Dordrecht, The Netherlands, 2011; pp. 805-821.

30. Vacik, H.; Borges, J.; Garcia-Gonzalo, J.; Eriksson, L.O. Decision Support for the Provision of Ecosystem Services under Climate Change: An Editorial. Forests 2015, 6, 3212-3217. [CrossRef]

31. Ferrández-Pastor, F.J.; García-Chamizo, J.M.; Nieto-Hidalgo, M.; Mora-Martínez, J. Precision agriculture design method using a distributed computing architecture on internet of things context. Sensors 2018, 18, 1731. [CrossRef]

32. Roy, S.; Ray, R.; Roy, A.; Sinha, S.; Mukherjee, G.; Pyne, S.; Mitra, S.; Basu, S.; Hazra, S. IoT, big data science \& analytics, cloud computing and mobile app based hybrid system for smart agriculture. In Proceedings of the 2017 IEEE 8th Annual Industrial Automation and Electromechanical Engineering Conference (IEMECON), Bangkok, Thailand, 16-18 August 2017; pp. 303-304.

33. Pajares, G. Advances in sensors applied to agriculture and forestry. Sensors 2011, 11, 8930-8932. [CrossRef] [PubMed]

34. Radoglou-Grammatikis, P.; Sarigiannidis, P.; Lagkas, T.; Moscholios, I. A compilation of UAV applications for precision agriculture. Comput. Netw. 2020, 172, 107148. [CrossRef]

35. Mananze, S.; Pôças, I.; Cunha, M. Mapping and Assessing the Dynamics of Shifting Agricultural Landscapes Using Google Earth Engine Cloud Computing, a Case Study in Mozambique. Remote Sens. 2020, 12, 1279. [CrossRef]

36. Say, S.M.; Keskin, M.; Sehri, M.; Sekerli, Y.E. Adoption of precision agriculture technologies in developed and developing countries. Online J. Sci. Technol. 2018, 8, 7-15.

37. Cook, S.E.; O'Brien, R.; Corner, R.J.; Oberthur, T.; Stafford, J.; Werner, A. Is precision agriculture irrelevant to developing countries. In European Conference on Precision Agriculture; Wageningen Academic Publishers: Wageningen, The Netherlands, 2003; pp. 115-120.

38. Gurjar, G.; Swami, S.; Lyngdoh, E.; Laitonjam, N.; Kant, K.; Singh, S.; Olaniya, M. Climate Change and Mixed Crop Livestock Farming Systems in Developing Countries: Importance and Impacts. Int. J. Curr. Microbiol. App. Sci 2018, 7, $3841-3845$.

39. Shaner, W.W. Farming Systems Research and Development: Guidelines for Developing Countries; Westview Press: Boulder, CO, USA, 2019.

40. Singh, S.; Saxena, K.; Singh, K.; Kumar, H.; Kadian, V. Consistency in income and employment generation in various farming systems. Ann. Agril. Res. 1997, 18, 340-343.

41. Behera, U.; France, J. Integrated farming systems and the livelihood security of small and marginal farmers in India and other developing countries. In Advances in Agronomy; Academic Press: Cambridge, MA, USA, 2016; Volume 138, pp. $235-282$.

42. Lightfoot, C. Integration of Aquaculture and Agriculture: A Route to Sustainable Farming Systems. Naga ICLARM Q. 1990, 13, 9-12.

43. Lytos, A.; Lagkas, T.; Sarigiannidis, P.; Zervakis, M.; Livanos, G. Towards smart farming: Systems, frameworks and exploitation of multiple sources. Comput. Netw. 2020, 172, 107147. [CrossRef]

44. Coble, K.H.; Mishra, A.K.; Ferrell, S.; Griffin, T. Big data in agriculture: A challenge for the future. Appl. Econ. Perspect. Policy 2018, 40, 79-96. [CrossRef]

45. Kakamoukas, G.; Sariciannidis, P.; Livanos, G.; Zervakis, M.; Ramnalis, D.; Polychronos, V.; Karamitsou, T.; Folinas, A.; Tsitsiokas, N. A Multi-collective, IoT-enabled, Adaptive Smart Farming Architecture. In Proceedings of the 2019 IEEE International Conference on Imaging Systems and Techniques (IST), Abu Dhabi, UAE, 9-10 December 2019; pp. 1-6.

46. Pham, X.; Stack, M. How data analytics is transforming agriculture. Bus. Horizons 2018, 61, 125-133. [CrossRef] 
47. Tropea, M.; Santamaria, A.F.; Potrino, G.; De Rango, F. Bio-Inspired Recruiting Protocol for FANET in Precision Agriculture Domains: Pheromone Parameters Tuning. In Proceedings of the IEEE 2019 Wireless Days (WD), Manchester, UK, 24-26 April 2019; pp. 1-6.

48. Morais, R.; Silva, N.; Mendes, J.; Adão, T.; Pádua, L.; López-Riquelme, J.A.; Pavón-Pulido, N.; Sousa, J.J.; Peres, E. Mysense: A comprehensive data management environment to improve precision agriculture practices. Comput. Electron. Agric. 2019, 162, 882-894. [CrossRef]

49. Rusinamhodzi, L.; Dahlin, S.; Corbeels, M. Living within their means: Reallocation of farm resources can help smallholder farmers improve crop yields and soil fertility. Agric. Ecosyst. Environ. 2016, 216, 125-136. [CrossRef]

50. Van Wijk, M.T.; Tittonell, P.; Rufino, M.C.; Herrero, M.; Pacini, C.; De Ridder, N.; Giller, K.E. Identifying key entry-points for strategic management of smallholder farming systems in sub-Saharan Africa using the dynamic farm-scale simulation model NUANCES-FARMSIM. Agric. Syst. 2009, 102, 89-101. [CrossRef]

51. Holzworth, D.; Huth, N.I.; Fainges, J.; Brown, H.; Zurcher, E.; Cichota, R.; Verrall, S.; Herrmann, N.I.; Zheng, B.; Snow, V. APSIM Next Generation: Overcoming challenges in modernising a farming systems model. Environ. Model. Softw. 2018, 103, 43-51. [CrossRef]

52. França, J.E.; Hollnagel, E.; dos Santos, I.J.L.; Haddad, A.N. Analysing human factors and non-technical skills in offshore drilling operations using FRAM (functional resonance analysis method). Cogn. Technol. Work. 2020. [CrossRef]

53. Dumont, A.M.; Vanloqueren, G.; Stassart, P.M.; Baret, P.V. Clarifying the socioeconomic dimensions of agroecology: Between principles and practices. Agroecol. Sustain. Food Syst. 2016, 40, 24-47. [CrossRef]

54. Rinaldi, F.; Jonsson, R.; Sallnäs, O.; Trubins, R. Behavioral modelling in a decision support system. Forests 2015, 6, 311-327. [CrossRef]

55. Loevinsohn, M.; Sumberg, J.; Diagne, A.; Whitfield, S. Under What Circumstances and Conditions Does Adoption of Technology Result in Increased Agricultural Productivity? A Systematic Review; Institute of Development Studies: Brighton, UK, 2013.

56. Consortium, Q. Networking our way to better ecosystem service provision. Trends Ecol. Evol. 2016, 31, 105-115.

57. Bacon, C.M.; Getz, C.; Kraus, S.; Montenegro, M.; Holland, K. The social dimensions of sustainability and change in diversified farming systems. Ecol. Soc. 2012, 17, 41. [CrossRef]

58. Moraine, M.; Duru, M.; Therond, O. A social-ecological framework for analyzing and designing integrated crop-livestock systems from farm to territory levels. Renew. Agric. Food Syst. 2017, 32, 43-56. [CrossRef]

59. Kuehne, G.; Llewellyn, R.; Pannell, D.J.; Wilkinson, R.; Dolling, P.; Ouzman, J.; Ewing, M. Predicting farmer uptake of new agricultural practices: A tool for research, extension and policy. Agric. Syst. 2017, 156, 115-125. [CrossRef]

60. Borges, J.A.R.; Lansink, A.G.O.; Ribeiro, C.M.; Lutke, V. Understanding farmers' intention to adopt improved natural grassland using the theory of planned behavior. Livest. Sci. 2014, 169, 163-174. [CrossRef]

61. Courtney, P.; Mills, J.; Gaskell, P.; Chaplin, S. Investigating the incidental benefits of Environmental Stewardship schemes in England. Land Use Policy 2013, 31, 26-37. [CrossRef]

62. Troussard, X.; van Bavel, R. How can behavioural insights be used to improve EU policy? Intereconomics 2018, 53, 8-12. [CrossRef]

63. Dessart, F.J.; van Bavel, R. Two converging paths: Behavioural sciences and social marketing for better policies. J. Soc. Mark. 2017, 7, 355-365. [CrossRef]

64. Floress, K.; de Jalón, S.G.; Church, S.P.; Babin, N.; Ulrich-Schad, J.D.; Prokopy, L.S. Toward a theory of farmer conservation attitudes: Dual interests and willingness to take action to protect water quality. J. Environ. Psychol. 2017, 53, 73-80. [CrossRef]

65. Insights, O.B.; Policy, P. Lessons from Around the World; OECD: Paris, France, 2017.

66. Villanueva, A.; Rodríguez-Entrena, M.; Arriaza, M.; Gómez-Limón, J. Heterogeneity of farmers' preferences towards agrienvironmental schemes across different agricultural subsystems. J. Environ. Plan. Manag. 2017, 60, 684-707. [CrossRef]

67. Schlüter, M.; Baeza, A.; Dressler, G.; Frank, K.; Groeneveld, J.; Jager, W.; Janssen, M.A.; McAllister, R.R.; Müller, B.; Orach, K.; et al. A framework for mapping and comparing behavioural theories in models of social-ecological systems. Ecol. Econ. 2017, 131, 21-35. [CrossRef]

68. Bonaudo, T.; Bendahan, A.B.; Sabatier, R.; Ryschawy, J.; Bellon, S.; Leger, F.; Magda, D.; Tichit, M. Agroecological principles for the redesign of integrated crop-livestock systems. Eur. J. Agron. 2014, 57, 43-51. [CrossRef]

69. Sempore, A.W.; Andrieu, N.; Le Gal, P.Y.; Nacro, H.B.; Sedogo, M.P. Supporting better crop-livestock integration on small-scale West African farms: A simulation-based approach. Agroecol. Sustain. Food Syst. 2016, 40, 3-23. [CrossRef]

70. Carauta, M.; Latynskiy, E.; Mössinger, J.; Gil, J.; Libera, A.; Hampf, A.; Monteiro, L.; Siebold, M.; Berger, T. Can preferential credit programs speed up the adoption of low-carbon agricultural systems in Mato Grosso, Brazil? Results from bioeconomic microsimulation. Reg. Environ. Chang. 2018, 18, 117-128. [CrossRef]

71. Soulignac, V.; Pinet, F.; Lambert, E.; Guichard, L.; Trouche, L.; Aubin, S. GECO, the French web-based application for knowledge management in agroecology. Comput. Electron. Agric. 2019, 162, 1050-1056. [CrossRef]

72. Soulignac, V.; Ermine, J.L.; Paris, J.L.; Devise, O.; Chanet, J.P. A knowledge management system for exchanging and creating knowledge in organic farming. Electron. J. Knowl. Manag. 2012, 10, 163.

73. Knierim, A.; Kernecker, M.; Erdle, K.; Kraus, T.; Borges, F.; Wurbs, A. Smart farming technology innovations-Insights and reflections from the German Smart-AKIS hub. NJAS-Wagening. J. Life Sci. 2019, 90, 100314. [CrossRef]

74. Reiff, M.; Surmanová, K.; Balcerzak, A.P.; Pietrzak, M.B. Multiple criteria analysis of European Union agriculture. J. Int. Stud. 2016, 9, 62-74. [CrossRef] [PubMed] 
75. Van Oost, I. The European Innovation Partnership (EIP) “Agricultural Productivity and Sustainability" Speeding up Innovation. In Proceedings of the "Added Value of Cooperation in Bioeconomy Research" International Bioeast Conference, Budapest, Hungary, 20 September 2017. Available online: https:/ /www.biosfere.be/wp-content/uploads/2017/12/Transmango-conferenceLeuven-Inge-Van-Oost.pdf (accessed on 30 December 2020)

76. Adinarayana, J.; Sudharsan, D.; Tripathy, A.; Sawant, S.; Merchant, S.; Desai, U.; Kiura, T. GEOSENSE: An information communication and dissemination system for decision support in precision farming. In Proceedings of the agro-informatics and precision agriculture (AIPA), Hyderabad, India, 1-3 August 2012; pp. 194-200.

77. Tamayo, R.A.C.; Ibarra, M.L.; Macías, J.A.G. Better crop management with decision support systems based on wireless sensor networks. In Proceedings of the IEEE 2010 7th International Conference on Electrical Engineering Computing Science and Automatic Control, Tuxtla Gutierrez, Mexico, 8-10 September 2010; pp. 412-417.

78. Jiber, Y.; Harroud, H.; Karmouch, A. Precision agriculture monitoring framework based on WSN. In Proceedings of the IEEE 2011 7th International Wireless Communications and Mobile Computing Conference, Istanbul, Turkey, 4-8 July 2011; pp. $2015-2020$.

79. Aiello, G.; Giovino, I.; Vallone, M.; Catania, P.; Argento, A. A decision support system based on multisensor data fusion for sustainable greenhouse management. J. Clean. Prod. 2018, 172, 4057-4065. [CrossRef]

80. Grigera, J.; Garrido, A.; Zaraté, P.; Camilleri, G.; Fernández, A. A mixed usability evaluation on a multi criteria group decision support system in agriculture. In Proceedings of the XIX International Conference on Human Computer Interaction, Palma, Spain, 12-14 September 2018; pp. 1-4.

81. Eves, A.; Stewart, T.P.; Gay, A.P.; Kemp, A.; Easey, M.; Angel, R.; Thomas, N.; Pearce, D. Developing unmanned aerial vehicles for local and flexible environmental and agricultural monitoring. In Proceedings of the New Dimensions in Earth Observation. Remote Sensing and Photogrammetry Society Conference, Leicester, UK, 8-11 September 2009.

82. Kakamoukas, G.A.; Sarigiannidis, P.G.; Economides, A.A. FANETs in Agriculture-A routing protocol survey. Internet Things 2020, 100183. [CrossRef]

83. Pajares, G. Overview and current status of remote sensing applications based on unmanned aerial vehicles (UAVs). Photogramm. Eng. Remote. Sens. 2015, 81, 281-330. [CrossRef]

84. Basist, A.; Dinar, A.; Blankespoor, B.; Bachiochi, D.; Houba, H. Use of satellite information on wetness and temperature for crop yield prediction and river resource planning. In Climate Smart Agriculture; Springer: Cham, Switzerland, 2018 ; pp. 77-104.

85. Li, P.; Wang, J. Research progress of intelligent management for greenhouse environment information. Nongye Jixie Xuebao Trans. Chin. Soc. Agric. Mach. 2014, 45, 236-243.

86. Wolfert, S.; Ge, L.; Verdouw, C.; Bogaardt, M.J. Big data in smart farming-a review. Agric. Syst. 2017, 153, 69-80. [CrossRef]

87. Muangprathub, J.; Boonnam, N.; Kajornkasirat, S.; Lekbangpong, N.; Wanichsombat, A.; Nillaor, P. IoT and agriculture data analysis for smart farm. Comput. Electron. Agric. 2019, 156, 467-474. [CrossRef]

88. Corrigan, S.; Martensson, L.; Kay, A.; Okwir, S.; Ulfvengren, P. Implementing collaborative decision making in European airports: challenges \& recommendations. J. Cognit. Technol. Work 2015, 17, 1435-5558.

89. Dessart, F.J.; Barreiro-Hurlé, J.; van Bavel, R. Behavioural factors affecting the adoption of sustainable farming practices: A policy-oriented review. Eur. Rev. Agric. Econ. 2019, 46, 417-471. [CrossRef]

90. Baumgart-Getz, A.; Prokopy, L.S.; Floress, K. Why farmers adopt best management practice in the United States: A meta-analysis of the adoption literature. J. Environ. Manag. 2012, 96, 17-25. [CrossRef]

91. Dwyer, J.; Mills, J.; Ingram, J.; Taylor, J.; Burton, R.; Blackstock, K.; Slee, B.; Brown, K.; Schwarz, G.; Matthews, K.; et al. Understanding and Influencing Positive Behaviour Change in Farmers and Land Managers; CCRI, Macaulay Institute: Gloucester, UK, 2007.

92. Colen, L.; Gomez y Paloma, S.; Latacz-Lohmann, U.; Lefebvre, M.; Préget, R.; Thoyer, S. Economic experiments as a tool for agricultural policy evaluation: Insights from the European CAP. Can. J. Agric. Econ./Rev. Can. D'Agroeconomie 2016, 64, 667-694. [CrossRef]

93. Higgins, N.; Hellerstein, D.; Wallander, S.; Lynch, L. Economic Experiments for Policy Analysis and Program Design: A Guide for Agricultural Decisionmakers; Technical Report; Economic Research Service Economic Research Report Number 236; Department of Agriculture: Washington DC, USA, 2017.

94. Jones, J.W.; Antle, J.M.; Basso, B.; Boote, K.J.; Conant, R.T.; Foster, I.; Godfray, H.C.J.; Herrero, M.; Howitt, R.E.; Janssen, S.; et al. Brief history of agricultural systems modeling. Agric. Syst. 2017, 155, 240-254. [CrossRef]

95. Van Calker, K.; Berentsen, P.; De Boer, I.; Giesen, G.; Huirne, R. An LP-model to analyse economic and ecological sustainability on Dutch dairy farms: Model presentation and application for experimental farm "de Marke". Agric. Syst. 2004, 82, 139-160. [CrossRef]

96. Wallander, S.; Ferraro, P.; Higgins, N. Addressing participant inattention in federal programs: A field experiment with the conservation reserve program. Am. J. Agric. Econ. 2017, 99, 914-931. [CrossRef]

97. Lacombe, C.; Couix, N.; Hazard, L. Designing agroecological farming systems with farmers: A review. Agric. Syst. 2018, 165, 208-220. [CrossRef]

98. Albahli, S.; Melton, A. Rdf data management: A survey of rdbms-based approaches. In Proceedings of the 6th International Conference on Web Intelligence, Mining and Semantics, Nîmes, France, 13-15 June 2016; pp. 1-4.

99. Mahlein, A.K.; Oerke, E.C.; Steiner, U.; Dehne, H.W. Recent advances in sensing plant diseases for precision crop protection. Eur. J. Plant Pathol. 2012, 133, 197-209. [CrossRef] 
100. Jones, H.; Schofield, P. Thermal and other remote sensing of plant stress. Gen. Appl. Plant Physiol. 2008, 34, 19-32.

101. Majumdar, J.; Naraseeyappa, S.; Ankalaki, S. Analysis of agriculture data using data mining techniques: application of big data. J. Big Data 2017, 4, 20. [CrossRef]

102. Rumpf, T.; Mahlein, A.K.; Steiner, U.; Oerke, E.C.; Dehne, H.W.; Plümer, L. Early detection and classification of plant diseases with support vector machines based on hyperspectral reflectance. Comput. Electron. Agric. 2010, 74, 91-99. [CrossRef]

103. Patel, N.; Yadav, K. Monitoring spatio-temporal pattern of drought stress using integrated drought index over Bundelkhand region, India. Nat. Hazards 2015, 77, 663-677. [CrossRef]

104. Putri, A.; Sitanggang, I. Data Cubes Integration in Spatial OLAP for Agricultural Commodities; IOP Conference Series: Earth and Environmental Science; IOP Publishing: Bristol, UK, 2017; Volume 58, pp. 1755-1755.

105. Islam, M.S.; Grönlund, Å. Agriculture market information services (AMIS) in the least developed countries (LDCs): Nature, scopes, and challenges. In Proceedings of the International Conference on Electronic Government, Lausanne, Switzerland, 29 August-2 September 2010; Springer: Dordrecht, The Netherlands, 2010; pp. 109-120. 